\title{
História pública, espaço urbano e memorialização de elites: o Museu Campbell House em St. Louis (EUA)
}

Public History, Urban Space and Memorialization of Elites: The Campbell House Museum in St. Louis (USA)

Resenha de: KOLK, Heidi Aronson. Taking possession: The Politics of Memory in a St. Louis Town House. Amherst. University of Massachusetts Press, 2019. 244 p.

Em Tomando posse: as políticas de memória em uma casa em St. Louis (tradução livre), Heidi Kolk, professora da Washington University (St. Louis), analisa as políticas da memória e o processo de musealização da Campbell House, edificação localizada na cidade de St. Louis, no estado americano do Missouri. A casa, datada de 1851 e situada no antigo bairro exclusivo conhecido por Lucas Place, foi a residência de Robert Campbell - empresário e membro das elites locais -, sua esposa Virginia e seus filhos, Hugh e Hazlett. A residência dos Campbell foi transformada na Campbell House Museum (Casa-Museu Campbell), oficialmente aberta ao público em 1943.

O trabalho de Kolk pode ser compreendido como um estudo exemplar de história pública, analisando as ações e engajamentos de um conjunto diverso de agentes sociais para a produção da memória e de significados sobre o passado na esfera pública. Articulando um leque amplo de perspectivas teórico-analíticas - como história pública, história urbana, museologia, geografia cultural, antropologia e sociologia -, o estudo interdisciplinar de Kolk, estruturado em oito capítulos, considera os principais acontecimentos históricos e "atos de apropriação" da Campbell House, desenrolados ao longo de aproximadamente um século e meio. Para o desenvolvimento do estudo, a autora baseia-se primordialmente numa análise da cultura material e dos objetos que

\footnotetext{
* Universidade Federal do Rio Grande do Sul (UFRGS), Porto Alegre, RS, Brasil. lucas_3106@hotmail. com <http://orcid.org/0000-0001-9789-7851>
} 
constituem as coleções e o acervo do Museu, além de documentos históricos e textos jornalísticos divulgados na imprensa.

O processo de musealização da Campbell House teve início com Hugh Campbell, herdeiro do patriarca da família, Robert. Visando proteger seu irmão de perturbações decorrentes de uma reconfiguração do espaço doméstico (Hazlett possuía uma saúde mental debilitada), Hugh tomou medidas para a preservação da estrutura e da disposição dos objetos da casa. Após o falecimento dos irmãos Hugh e Hazlett, os objetos dos Campbell foram submetidos a um leilão, em 1941. A William Clark Society, grupo preservacionista composto por elites culturais e empresariais locais, adquiriu parte significativa dos objetos dos Campbell, com o intuito de transformar a antiga residência em um lugar de memória. Em 1943, o Museu foi aberto ao público, passando a ser administrado pela recém-fundada Campbell House Foundation. O último acontecimento decisivo na história do Museu foi a descoberta de um álbum de fotografias da Campbell House, com datação de ca. 1885, o que motivou uma restauração completa da instituição no início dos anos 2000, originada de uma preocupação com a integridade material e a autenticidade das coleções e exposições do Museu.

Um dos maiores méritos da obra de Kolk é a inserção da Campbell House no espaço urbano de St. Louis. A análise das políticas de memória leva em conta as tensões e dinâmicas de constituição da cidade, além de considerar as imagens produzidas e associadas a ela pelas elites locais. De acordo com Kolk, a Campbell House é um "vestígio do passado", uma sobrevivente "improvável" em uma cidade que vivenciou inúmeros projetos de renovação e limpeza urbana, o que acarretou a destruição completa de bairros históricos - especialmente de classe trabalhadora ou racialmente demarcados -, bem como a migração das elites do centro urbano em direção aos subúrbios. Assim, um fenômeno supostamente paradoxal - a sobrevivência de uma casa histórica datada de meados do século XIX, em um contexto marcado pelo ímpeto de "modernização" que caracteriza a história de St. Louis -, adquire inteligibilidade quando levamos em conta que a preservação da casa se insere no mesmo esforço de ordenamento do espaço urbano levado a cabo pelas elites locais, visando controlar uma cidade aparentemente desgovernada.

A Campbell House foi alvo do trabalho de memorialização das elites locais, na medida em que se constitui como uma representação do passado glorioso de St. Louis. Isto é, a casa opera como um monumento à era de ouro da cidade, o grandioso período vitoriano nos anos 1850, quando a cidade era um centro de comércio e colonização, vivenciando abundância material e prestígio nacio- 
nal. St. Louis era, então, considerada o último posto de "civilização" na fronteira americana, o seu "portal para o Oeste". Segundo Kolk, a memória de um passado glorioso - encarnada e materializada pela Campbell House - contrasta com as dificuldades atuais de St. Louis, uma cidade em declínio caracterizada por problemas sociais e econômicos, como a pobreza, os altos índices de violência e a desigualdade racial. Nesse sentido, podemos analisar a Campbell House e seu esforço de "nostalgia restaurativa" à luz do paradoxo característico do lugar de memória, na célebre formulação de Pierre Nora (1993), isto é, que a consagração de lugares específicos à memória se deve precisamente ao fato de a memória não ser mais um elemento estruturante das práticas sociais de determinado grupo social. Em outras palavras, a Campbell House é a representação de um passado glorioso em um momento de decadência e ausência de grandiosidade; ao atestar as grandezas passadas de St. Louis, o Museu demonstra implicitamente as vulnerabilidades da cidade no presente.

Outro elemento da reflexão de Kolk digno de nota é a atenção despendida aos interesses econômicos subjacentes ao apoio e à promoção da memória. A aquisição e doação da residência dos Campbell foi operada pela Stix, Baer \& Fuller, uma loja de varejo situada nas proximidades da casa. Esse ato desinteressado (Bourdieu, 1996), em que a companhia presenteava a cidade de St. Louis com um Museu, adquire maior complexidade quando se considera, por exemplo, o uso da imagem da Campbell House em campanhas publicitárias veiculadas pela empresa. A análise de Kolk, assim, acentua a necessária vigilância dos estudiosos da história quanto aos múltiplos interesses envolvidos na promoção da memória, que adquire ainda mais relevância se considerarmos o contexto recente de disseminação do investimento de empresas e elites empresariais na esfera da memória (Kerber; Ott, 2014).

Uma das maiores fragilidades do trabalho de Kolk é a ausência de um tratamento adequado de trajetórias e biografias sociais. É apenas no penúltimo capítulo que o leitor descobre os meandros da aquisição da fortuna de Robert Campbell no comércio de peles; não obstante, tal discussão não se baseia numa análise sistemática da trajetória profissional do agente, mas na problematização de uma radionovela sobre a vida de Campbell, veiculada em 1948. Ademais, Robert era um imigrante irlandês. Conquanto a experiência migratória se mostre, via de regra, um fato extremamente significativo a qualquer biografia, o fenômeno carece de tratamento analítico pela autora. De modo geral, as menções aos membros da família Campbell ao longo da obra são episódicas e pouco aprofundadas. Sendo assim, a lacuna constatada por Kolk na narrativa produzida e veiculada pelo Museu Campbell House - isto é, a ausência da história 
familiar - pode ser imputada à narrativa textual e acadêmica elaborada pela própria autora.

Em sentido semelhante, o trabalho de Kolk executa menções ocasionais e en passant - consistindo basicamente na exposição dos nomes próprios e da profissão exercida - aos membros da William Clark Society e da Campbell House Foundation, agentes multiposicionados que integravam as elites culturais e empresariais de St. Louis. Dessa forma, a análise de Kolk, muitas vezes de estilo literário, ganharia robustez caso introduzisse uma discussão mais profunda na interface com os campos da história social e da sociologia, desenvolvendo uma análise da biografia coletiva dos agentes engajados no esforço de promoção da memória em St. Louis. Tal análise prosopográfica (Stone, 2011) possibilitaria uma compreensão mais adequada dos interesses das elites locais de St. Louis na esfera da memória, das propriedades sociais responsáveis pelo engajamento dos agentes na preservação histórica, das formas de mobilização da memória nas agendas específicas dos agentes - econômicas, políticas, culturais -, e dos modos de utilização da memória na produção da autoimagem dos agentes enquanto grupo dominante local.

Ainda assim, a obra de Kolk mostra-se uma leitura profícua e de interesse especialmente aos estudiosos da história, museologia, sociologia e antropologia. O Museu Campbell House foi historicamente um espaço de produção e disseminação de narrativas por parte das elites e das classes médias, em uma cidade marcada por problemas sociais e pela segregação urbana. Assim, o estudo de caso sobre um museu local de St. Louis adquire relevância em função de sua exemplaridade, podendo auxiliar estudiosos na compreensão do museu e da memória em seu contexto espacial e urbano mais amplo. Ademais, a análise dos "atos de apropriação" do patrimônio cultural e histórico pode elucidar o papel e as estratégias das elites na produção de significados sobre o passado, a cidade e seus "legítimos" porta-vozes e representantes.

\section{REFERÊNCIAS}

BOURDIEU, Pierre. É possível um ato desinteressado? In: BOURDIEU, Pierre. Razões práticas: sobre a teoria da ação. Campinas: Papirus, 1996. p. 137-156.

KERBER, Alessander; OTT, Fernanda. A construção da história e da memória em empresas privadas no Brasil dos anos 1990 e 2000. Revista Esboços, Florianópolis, v. 21, n. 31, p. 219-235, 2014.

NORA, Pierre. Entre memória e história: a problemática dos lugares. Projeto História, São Paulo, v. 10, p. 7-28, 1993. 
História pública, espaço urbano e memorialização de elites: o Museu Campbell House em St. Louis

STONE, Lawrence. Prosopografia. Revista de Sociologia e Política, Curitiba, v. 19, n. 39, p. 115-137, 2011.

\section{Nota}

${ }^{1}$ Visiting Scholar no Lemann Center for Brazilian Studies da University of Illinois at Urbana-Champaign (UIUC, Champaign, IL, Estados Unidos). Bolsita da Coordenação de Aperfeiçoamento de Pessoal de Nível Superior.

Resenha recebida em 13 de abril de 2020. Aprovada em 3 de julho de 2020. 